\title{
Electrophysiologic study in chronic Chagas' heart disease
}

\author{
Heart Institute, Hospital das Clínicas, Faculdade de Medicina da \\ Universidade de São Paulo - São Paulo, Brazil
}

\begin{abstract}
Cardiac arrhythmias are common in chagasic patients. Electrophysiologic study is an invasive procedure for the investigation of sinus node function, atrioventricular node conduction and intraventricular (His-Purkinje) conduction and the mechanism of tachycardias. It is useful in elucidating syncope, dizziness and tachycardiac palpitations that remain unexplained by non-invasive diagnostic methods. It is fundamental in directing non-pharmacological therapy, especially in "sudden death" survivors. Chagasic patients may benefit from electrophysiologic study after a critical clinical evaluation.
\end{abstract}

UNITERMS: Electrophysiologic study. Cardiac arrhythmias. Chagas' heart disease.

$\mathrm{D}$ uring the evolution of chronic chagasic cardiopathy, patients can present clinical complications secondary to cardiac arrhythmias. The clinical manifestations vary from dizziness, nearsyncopal symptoms, paroxysmal palpitations, to even syncopes and sudden death. Sure diagnosis is accomplished through electrophysiologic documentation of the occurrence, though this is not always possible, and sometimes the therapeutic decision has to be made without

\author{
Address for correspondence: \\ Maurício Scanavacca \\ Instituto do Coração, Hospital das Clínicas \\ Faculdade de Medicina da Universidade de São Paulo \\ Av. Dr. Enéas de Carvalho Aguiar, 44 \\ Såo Paulo - SP - Brasil - CEP 05403-000
}

auxiliary methods. Among these methods are: ECG of long duration (Holter), exercise ECG, high resolution ECG and electrophysiologic study.

Electrophysiologic study is an invasive procedure, performed by captivation of intracavity electrograms, analyzed during spontaneous cardiac rhythm and during programmed electric stimulation of the atria and ventricles. With this technique we evaluated the function of the sinus node, the conduction through the atrioventricular node, the conduction through the His-Purkinje system and the mechanism of tachyarrhythmias. The objective of this study is to present the current applications of electrophysiologic study in patients with chronic chagasic cardiopathy.

There is a consensus about indications for electrophysiologic study as an auxiliary method in the diagnosis of patients with cardiac arrhythmias (31). Indications are directed toward specific groups of 
arrhythmias (evaluation of sinus function, of atrioventricular and intraventricular conduction, of mechanism and localization of the point of origin of tachycardias with narrow and wide QRS) or for clinical syndromes (unexplained syncope, survivors of cardiac arrest, for clarification of tachycardiac palpitations etc.).

Indication for electrophysiologic study directed toward a specific cardiopathy is controversial. Ischemic cardiopathy has received more attention in investigative studies, so the most of the indications for electrophysiologic study related to it are already established (3). In chronic chagasic cardiopathy, there has been no specific discussion on this matter, so the amount of information is limited. At the moment there are two applications of electrophysiologic study in chronic chagasic cardiopathy: 1) As a method of investigation of specific arrhythmias, aiming as a basic objective a physiopathological comprehension of the mechanisms involved; 2) As an aid in the clinical handling of patients with cardiac arrhythmias, where it is used as a diagnostic method, and for therapeutic orientation. In this article we will discuss only the second aspect, relating the clinical applications of electrophysiologic study to chronic chagasic cardiopathy.

Indication for electrophysiologic study with chronic chagasic cardiopathy should be individualized. This decision depends on the clinical characteristics of the patient with chronic chagasic cardiopathy and on the evaluation as to how much the electrophysiologic study could help clarify the therapeutic decision. The technical and service capacities to apply the various nonpharmacological forms of therapy in the treatment of tachyarrhythmias, like surgical ablation, ablation by catheter, and implantation of automatic devices is a decisive factor. Another important question is related to security and the risks related to the use of the procedure. We point out that our procedures have been elaborated over the last 15 years, and, after using electrophysiologic study in the evaluation of more than 3,000 patients, 500 of whom with chronic chagasic cardiopathy, we can affirm that electrophysiologic study is a safe method with low morbidity when applied within the recommended norms (16), and it is of great use in the handling of chagasic patients, when well selected.

\section{DYSFUNCTION OF THE SINUS NODE}

The electrophysiologic tests routinely used for evaluation of the sinus node function are: the corrected recuperation time of the sinus node (22), and the time of sinoatrial conduction (43). When combined, the sensitivity and specificity of these tests are estimated at $68 \%$ and $88 \%$ respectively (31). Maia et al. (21), and Pimenta et al. (29), when applying these techniques in carriers of chronic chagasic cardiopathy, found signs of sinus dysfunction in $30 \%$ and $18.1 \%$, respectively.

In general, electrophysiologic study is not needed to reach a therapeutic decision for patients with sinus node disease, with or without chronic chagasic cardiopathy. Indication for pacemaker implant is done based on the presence of symptoms related to bradyarrhythmia, normally documented by prolonged electrocardiographic monitoring (Holter's method).

Application of the sinus node evaluation tests can be useful in patients with a history of low cerebral output and where the 24 hour Holter test suggests some degree of sinus dysfunction without noting the occurrence of symptoms. The test is of indisputable value when it reproduces the symptom, but this is rarely seen. Electrophysiologic study can also help eliminate other electrophysiologic causes of syncope. Patients with asymptomatic sinus dysfunction that need antiarrhythmic drugs that are also potentially depressants of the sinus function can benefit from electrophysiologic evaluation. A prolonged sinus node recuperation time after use of the drug warns as to possible complications, suggesting special monitoring, sometimes requiring the implant of a temporary pacemaker (39).

\section{ATRIOVENTRICULAR CONDUCTION DEFECT}

As in the case of sinus node dysfunction, currently electrophysiologic study is rarely indicated for carriers of chronic chagasic cardiopathy in order to exclusively study the level of atrioventricular conduction blockage. Carriers of chronic chagasic cardiopathy with near-syncopal or syncope symptoms due to documented, high degree atrioventricular block are indicated for definitive pacemaker implantation, precluding the need for electrophysiologic study.

On the other hand, patients with asymptomatic chronic chagasic cardiopathy and atrioventricular defects rarely are indicated for electrophysiologic study. The risk of evolution to symptomatic bradycardia is related to the level of blockage of the atrioventricular system, and whether it is nodal (A-H interval) or of the His-Purkinje system ( $\mathrm{H}-\mathrm{V}$ interval). Conduction defects located in the 
atrioventricular junction normally evolve slowly and the progression can be monitored with the use of Holter's method. The blockages located in the His-Purkinje system could occur suddenly, with a smaller frequency escape rhythm, thus more symptomatic and higher risk.

In carriers of chronic chagasic cardiopathy, total atrioventricular block can be nodal, occurring in the trunk of the His bundle, after the His bundle or in associate form. The most common form however is located after the His bundle trunk (4). Localization of the atrioventricular block can be suggested in a non-invasive manner, through means of combined analysis of the width of the QRS complex, of the P-R interval behavior, of the atrioventricular conduction during exertion, and through the response to vagal maneuver and to atropine (23).

Carriers of chronic chagasic cardiopathy and atrioventricular conduction defect that could need electrophysiologic study are: 1) carriers of first and second degree atrioventricular block with unexplained symptoms, where besides investigating the level of blockage, the sinus node function and the possibility of the occurrence of tachyarrhythmias are also evaluated; 2) in asymptomatic patients with bifascicular block and first and second degree atrioventricular block, in order to identify the higher risk group (post-Hisian), when non-invasive evaluation is not revelatory.

\section{INTRAVENTRICULAR BLOCKS}

Carriers of chronic chagasic cardiopathy and intraventricular blocks demonstrate risk of total atrioventricular block. However, the progression toward high degree blocks, as observed in other cardiopathies, is gradual, with a low annual incidence $(11,25)$. At least three studies done on non-chagasic cardiopathies were unable to demonstrate clinical usefulness of $\mathrm{H}-\mathrm{V}$ interval mensuration in carriers of asymptomatic bifascicular blocks $(11,25)$.

This information has been used, in our group, in the handling of carriers of chronic chagasic cardiopathy, in such a way that only patients with bifascicular blocks and near-syncopal or syncope symptoms were submitted to evaluation of the reserve of the His-Purkinje system conduction. The following items are given weight: an $\mathrm{H}$ V- interval $>70 \mathrm{~ms}$, principally if it is $>100 \mathrm{~ms}$ (11); induction of post-Hisian block with atrial stimulation (25) or after intravenous infusion of $10 \mathrm{mg} / \mathrm{kg}$ of procainamide hydrochloride (32). Previous studies $(11,25)$, demonstrate that there was no reduction of mortality in patients with bifascicular blocks that received a pacemaker in comparison with those that remained under observation, although there was a statistically significant reduction in the occurrence of syncope. These data suggest that the mortality of these patients is related to: 1) the degree of myocardial aggression and the progression toward congestive cardiac insufficiency; and 2) sudden death that has been related to ventricular arrhythmias. Therefore, in carriers of intraventricular block and non-defined nearsyncopal symptoms, electrophysiologic study is fundamental in the investigation of the possible presence of ventricular tachycardias, in addition to evaluating the risk of progression toward total atrioventricular block.

\section{DIFFERENTIAL DIAGNOSIS OF TACHYCARDIAS}

In carriers of chronic chagasic cardiopathy the occurrence of tachycardiac palpitations should raise suspicions of paroxysmal ventricular tachycardia. However, nothing prevents these individuals from displaying supraventricular tachycardias, that could be secondary to the progressive dilation of the cardiac chambers (atrial tachycardias, flutter and atrial fibrillation) or tachycardias of the atrioventricular junction that normally occur in the general population via nodal re-entry and using accessory pathways. As it is estimated that between 3 and 5 million Brazilians are seropositive for Chagas' disease, and extrapolating that the incidence of tachycardias that involve the atrioventricular junction must be similar in endemic and non-endemic zones, it is expected that this association is not uncommon in Brazil. Pimenta et al. (30) identified a prevalence rate of $28 \%$ of parallel nodal pathways in asymptomatic chagasic patients who underwent electrophysiologic study. They suggested that this alteration could be related to a form of aggression by the disease of the atrioventricular junction. During programmed atrial stimulation they were able to induce nodal re-entry tachycardia in $25 \%$ of the patients with parallel conduction pathways, although without spontaneous occurrence in the follow-up.

When the tachycardia is documented on the ECG the diagnosis is relatively simple, principally when it displays a narrow QRS complex. However, since intraventricular conduction disturbances are common in chronic chagasic cardiopathy, these tachycardias can be seen with a wide QRS complex and can be initially 
confused with ventricular tachycardias. We had the opportunity to accompany a chagasic patient with an initial diagnosis of exercise-induced ventricular fibrillation. The electrophysiologic study revealed that, in reality, we were dealing with a patient with chronic chagasic cardiopathy, in its dilated form, with paroxysmal atrial fibrillation associated with Wolff-Parkinson-White syndrome with an accessory pathway with high antegrade conduction capacity.

Electrophysiologic study was often used to clarify the differential diagnosis of tachycardias with wide QRS complexes, but currently it is little used for this purpose. When paroxysmal tachycardia is documented with an electrocardiographic register of 12 derivations, minute analysis using the criteria described by Brugada et al. (16) can establish a diagnosis of ventricular tachycardia with an accuracy over $95 \%$. Recently, these criteria were tested on patients with chronic chagasic cardiopathy and sustained ventricular tachycardia. Applying the same criteria it was possible to establish a diagnosis of sustained ventricular tachycardia in $95 \%$ of the patients (27). However, indication for electrophysiologic study for diagnosis of paroxysmal tachycardiac palpitations is restricted to the following cases: 1 ) when non-invasive methods for documentation of the tachycardias are not possible; 2) when analysis of the register obtained does not allow definition of the diagnosis and ventricular tachycardia is suspected; 3 ) when the clinical manifestation is severe and a new spontaneous register cannot be awaited; and 4) rarely, when there has already been a diagnosis of supraventricular tachycardia established and the exam is indicated to define the mechanism and apply a catheter ablation technique, a fact observed in only 2 patients amongst 150 who underwent catheter ablation of accessory pathways.

\section{PAROXYSMAL VENTRICULAR TACHYCARDIA}

Paroxysmal ventricular tachycardia, secondary to chronic chagasic cardiopathy, is the principal cause of treatment of patients with sustained ventricular tachycardia in endemic regions and in reference centers that receive patients in these regions, such as the Heart Institute of São Paulo (Instituto do Coração, São Paulo). Of 554 patients with sustained ventricular tachycardia studied by us, 269 were carriers of chronic chagasic cardiopathy.
In 20 consecutive patients with sustained ventricular tachycardia and chronic chagasic cardiopathy subjected to programmed stimulation of the right ventricle, with protocol using two cycles (600 and $400 \mathrm{msec}$ ) with up to three extra-stimuli applied on the point and on the exit pathway, it was possible to reproduce sustained ventricular tachycardia in $85 \%$ of the patients and non-sustained (less than 30 seconds duration) ventricular tachycardia in another $5 \%$. These data demonstrate that electrophysiologic study is a reasonably precise and accurate method for reproducing ventricular tachycardia in carriers of chronic chagasic cardiopathy.

In chronic chagasic cardiopathy many evidences suggest that the principal mechanism of sustained ventricular tachycardia is re-entry, using myocardial tissue involved in areas of fibrosis or aneurysms, mostly in the left ventricle, predominantly in the basal region (inferolateral), followed by the septal and apical regions (45). In 72 carriers of chronic chagasic cardiopathy and frequent ventricular extrasystoles, with an average ejection fraction of the left ventricle of $60 \%$, and without spontaneous sustained ventricular tachycardia, programmed stimulation was not able to induce sustained ventricular tachycardia with a cardiac frequency of less than $270 \mathrm{bpm}$, in any patient. Throughout an average of 36 months of observation, only 1 patient displayed spontaneous sustained ventricular tachycardia. This patient underwent a new electrophysiologic study and it was not possible to re-induce clinical sustained ventricular tachycardia (a true false negative test). These data demonstrate that electrophysiologic study also displays high specificity of sustained ventricular tachycardia induction in chronic chagasic cardiopathy, at least in patients retaining ventricular function.

Electrophysiologic evaluation in patients with chronic chagasic cardiopathy and sustained ventricular tachycardia has two basic objectives: 1) to define the diagnosis, and 2) to direct therapy. Since most patients with sustained ventricular tachycardia that we receive display recurrent profiles and have already defined diagnosises, these patients undergo electrophysiologic study in order to establish a therapeutic strategy.

Currently carriers of chronic chagasic cardiopathy and sustained ventricular tachycardia can receive various forms of treatment, depending on the clinical state of the patient, on the electrophysiologic presentation of the tachycardia, and on the anatomic characteristics of the left ventricle, frequently involved in the tachycardia circuit. Pharmacological treatment has been the first therapy used, though methods used to evaluate the efficiency have generated controversy. It can be done by means of Holter 
and serial exercise tests (15), through serial programmed stimulation $(7,44)$, or through clinical follow-up and observation of spontaneous reoccurrences $(28,35)$. In the period between 1980 and 1985 , we used a combination of the first two methods, trying to individualize the use of antiarrhythmics. The patients remained hospitalized for 30 to 45 days in search of an efficient drug by means of these methods. After this period $90 \%$ of the patients were released with amyodarone due to the small number of drugs from which we could choose by means of programmed stimulation and to the fact that amyodarone displayed the best response to Holter evaluation, in spite of the fact that we continued to re-induce tachycardia in $80 \%$ of the patients who used it. On the other hand, in observations of a group of 35 patients with chronic chagasic cardiopathy and sustained ventricular tachycardia who could not receive this direction and who took amyodarone in an empirical manner in similar dosage (impregnation with $1200 \mathrm{mg} /$ day for 10 to 14 days and $400 \mathrm{mg} /$ day maintenance) a fairly favorable evolution was seen (42). Although there was a relapsine rate of $30 \%$ in the first year, the sudden death rate was very low and associated with accentuated ventricular dysfunction (42). From then on we stopped using programmed stimulation as a routine in the selection of antiarrhythmic drugs in carriers of chronic chagasic cardiopathy and sustained ventricular tachycardia. Carriers of recurrent sustained ventricular tachycardia, reproducible in electrophysiologic study, with good hemodynamic tolerance, are candidates for catheter ablation of the tachycardia circuit $(14,41)$. There are various techniques under investigation using high energy electric current, low energy current, radiofrequency or by means of alcoholization of the coronary artery that supplies the region of the circuit. Although the results of these procedures are promising, they are still not totally predictable. The various techniques are still in the development phase, though some patients who are refractory to pharmacological treatment already seem to be getting some benefit when well selected.

Carriers of chronic chagasic cardiopathy and recurrent sustained ventricular tachycardia who are refractory to antiarrhythmic drugs can be benefited from surgical treatment (40). The candidates should have anatomy favorable to surgery, characterized by areas of dyscinesia related to the tachycardia circuit and should still have residual left ventricular function. Electrophysiologic study is important for mapping the origin of the tachycardia and for confirmation of the relation to the dyscinetic area. After surgery, a control electrophysiologic study confirms the efficiency of the procedure or identifies the patients who need to use antiarrhythmic drugs (1).
The safest way to handle patients who had to be resuscitated due to ventricular tachyarrhythmia is through implant of a device with cardioversion capacity and automatic defibrillation (36). If the patient has anatomy favorable to surgery, surgical treatment is most indicated; however, if unsuccessful, the defibrillator protects the patient from sudden death. In patients with anatomy unfavorable to surgery, the defibrillator gives some security for the administration of antiarrhythmic drugs; in the case of accentuated ventricular dysfunction, it could serve as a "bridge" for the patient who awaits a heart transplant. The handling of the patient with an automatic defibrillator electrophysiologic study is important in the selection of parameters of tachycardiac identification, principally after association with antiarrhythmic drugs and in the evaluation of the efficiency of the device in interrupting tachycardias.

\section{SYNCOPE}

Carriers of cardiopathies who display syncope have a high risk of recurrence and sudden death (17). This risk is associated, most of the time, with the occurrence of cardiac arrhythmias. Electrophysiologic study has been used in carriers of syncope of unknown origin with noninvasive methods. In chagasic patients there are two studies done using electrophysiologic study $(2,24)$. Barbosa et al. (2) studied 9 patients with unexplained syncope and intraventricular conduction defect. They observed that induced sustained ventricular tachycardia was the principal electrophysiologic alteration found (55\%) while atrioventricular conduction defects were implicated in $33 \%$ of the cases (H-V interval $>70 \mathrm{~ms}$ ).

Martinelli (34) retrospectively studied 53 patients with chronic chagasic cardiopathy and recurrent syncopes unexplained by conventional evaluation. Intraventricular conduction defects were present in $80 \%$ of the patients and the average of the ejection fraction of the left ventricle was $54 \%$. Sustained ventricular tachycardia was induced in 25 patients $(47 \%), 10$ of them with prolonged $\mathrm{H}-\mathrm{V}$ interval ( $>70 \mathrm{~ms})$. They underwent directed treatment with antiarrhythmic drugs and in patients with the prolonged $\mathrm{H}-\mathrm{V}$ interval a permanent pacemaker was installed. In 11 patients $(21 \%)$, the prolonged $\mathrm{H}-\mathrm{V}$ interval was the only alteration found and they also received a permanent pacemaker. In 17 patients (32\%) the electrophysiologic study results were normal. These patients received antiarrhythmic drugs empirically. After an average period of 85 months of observation ( 2 to 127 months) the 
following evolution was observed: 1) in carriers of induced ventricular tachycardia there were $7(28 \%)$ relapses of syncope and $8(32 \%)$ deaths; 2 ) in carriers of isolated alteration of the $\mathrm{H}-\mathrm{V}$ interval who received pacemakers there were no deaths or relapses of syncope; and 3) in the group where the electrophysiologic study was negative, 6 $(35 \%)$ of the patients demonstrated relapses of syncope and $1(6 \%)$, sudden death. These data suggest that: 1) induction of sustained ventricular tachycardia in patients with chronic chagasic cardiopathy and unexplained syncope indicates a group with worse prognosis, in spite of the therapy instituted (drugs and pacemakers); 2) the implantation of a pacemaker was efficient in avoiding relapses in patients with prolonged $\mathrm{H}-\mathrm{V}$ interval when ventricular tachycardia was not induced; and 3 ) when the electrophysiologic study results are normal patients have a favorable prognosis, even though there may be frequent recurrent syncope. The causes involved could be related to automatic dysfunction which was not investigated in this paper, or to ventricular tachycardia that was not identified by electrophysiologic study. This last alternative is the least probable due to the low mortality observed in this group and the non-documentation of sustained ventricular tachycardia after such a long period of observation. In conclusion, electrophysiologic study is an efficient method of diagnostic clarification in patients with chronic chagasic cardiopathy and recurrent syncopes that are unexplained by conventional evaluation. An electrophysiologic disturbance can be found in approximately $70 \%$ of the patients, favoring therapeutic orientation.

\section{PATIENTS RESUSCITATED AFTER CARDIAC ARREST (SUDDEN DEATH)}

Sudden death is the leading cause of death in carriers of chronic chagasic cardiopathy (12). These patients rarely get sufficiently prompt medical attention; and with this, little is known as to the mechanisms involved in the event. There are at least three distinct populations of patients with chronic chagasic cardiopathy who could be susceptible to sudden death: 1) patients who display sudden death as the first symptom of cardiopathy; 2) carriers of recurrent sustained ventricular tachycardia and who experience sudden death in its evolution; and 3) carriers of congestive cardiac insufficiency who have sudden death as the last event. These patients present distinct clinical profiles and different physiopathological mechanisms. The first group is seen in endemic zones. In general they are men in the productive phase, without cardiac insufficiency, and who experience sudden death, sometimes as the first manifestation of the disease. Sustained ventricular tachycardia is the principal cause observed in documented cases. In general it is rapid, at times polymorphic, evolving into ventricular fibrillation, and it has been associated with physical and psychological stress (19). Lopes et al. (19) described the anatomopathological aspect of this group of patients. They noted that the heart had an "almost normal" appearance with mild hypertrophy, without dilation or significant dyscinetic areas, different from patients who died during the evolution of cardiac insufficiency (18).

We had the opportunity to study two patients with these clinical characteristics. Electrophysiologic study induced very rapid sustained ventricular tachycardia, which was poorly tolerated, and the antiarrhythmic drugs were incapable of preventing re-induction. Left ventriculography showed diffuse hypocontractability, mild to moderate. During clinical treatment sudden death occurred and they subsequently underwent anatomopathological study. The macroscopic aspect of the heart was similar to that related by Lopes, that is, without dilation, with mild hypertrophy, an absence of akinesia and, under the microscope, there was no significant inflammatory process. These patients displayed different clinical, electrophysiologic and anatomical characteristics than those of patients attended to at reference hospitals.

The second group is formed by patients who exhibit ventricular tachycardias with sufficient hemodynamic tolerance to be attended to in the hospitals and who represent a naturally selected group; they are male in $70 \%$ of the cases, with an average age of 50 and with previous symptoms of palpitations, near-syncope and less frequently, cardiac insufficiency. They behave like a "more benign" group by displaying a more satisfactory evolution even using antiarrhythmic drugs, since in spite of the reoccurrences, the incidence of sudden death is low (42). They become "malignant" when there is aggravation of the ventricular dysfunction and a consequent reduction in the hemodynamic tolerance and, in spite of the use of amyodarone, they end up dying suddenly (42). When these patients are subjected to an investigation of the anatomic substrate of the tachycardia, they commonly exhibit regional cardiopathy with areas of akinesia and dyscinesia, most often in the inferior-lateral-basal region, independent of the presence of apical lesion. With left and right oblique anterior ventriculography, they display similar alterations to those observed after myocardial infarction. 
The third group, formed by patients with advanced cardiac insufficiency due to severe ventricular dysfunction, distinguish themselves from the previous groups by the higher frequency of bradyarrhythmias as a cause of cardiac arrest. Liu et al. (20), documented the final event in 21 patients who were hospitalized awaiting heart transplants, 13 having cardiac insufficiency secondary to ischemic cardiopathy, and 7, to idiopathic dilated myocardiopathy. They were all hemodynamically compensated, receiving vasodilators (inhibitors of the conversion enzyme of angiotensin) and diuretics. The cause of cardiac arrest was bradyarrhythmia in 13 patients (62\%), asystole in 9 , total atrioventricular block in 2, ventricular tachycardia/ ventricular fibrillation in 8 patients (38\%), and in one of them ventricular fibrillation was preceded by bradycardia. The authors emphasize that there were diverse factors connected with the arrhythmias, such as pulmonary and coronary embolia, hyperpotassemia, hypoglycemia (in those patients with bradyarrhythmia), and acute myocardial infarction ( 2 patients with chronic coronary insufficiency) in the cases with tachyarrhythmia. This information cannot be carried over to patients with chronic chagasic cardiopathy, although it is possible that these mechanisms are involved in the etiopathology of the cardiac arrest in chagasic patients with cardiac insufficiency, even if partially.

The best way to deal with patients resuscitated from unexpected cardiac arrest is through evaluation of the clinical characteristics of the patients. Carriers of rapid tachycardias, poorly tolerated, with anatomical substrates that are not conducive to surgery, are indicated for the implantation of a cardioversor/automatic defibrillator, as the safest form of treatment in these cases. In our casework only three chagasic patients were able to benefit from implantation, due to the high cost of the equipment, which is not covered by any health insurance plan in Brazil. In these cases electrophysiologic study is fundamental in tests of the evaluation of the efficiency of the equipment and the evaluation of the effects of the antiarrhythmic drugs, which are frequently used, and can modify the tachycardiac cycle and the ventricular fibrillation threshold (37). Patients with slower tachycardias, with hemodynamic tolerance and ventricular function intact, are candidates for ablative treatment or the use of antiarrhythmic drugs initially. Finally, in those patients awaiting heart transplants and displaying malignant arrhythmias, the implant of an automatic fibrillator can provide security by reversion of possible episodes of ventricular tachycardia or fibrillation, though the device should be associated with an antibradyarrhythmic system (pacemaker).

\section{EVALUATION OF RISK IN PATIENTS WITH COMPLEX VENTRICULAR ARRHYTHMIAS}

The best treatment for patients with frequent ventricular extrasystoles is controversial. While on one hand there is consensus that carriers of frequent ventricular extrasystoles show a greater risk of sudden death (5), on the other hand it has been demonstrated that the use of class I drugs aggravates their degree of risk (13). Multicentric studies are trying to answer if amyodarone can be beneficial in patients with frequent and complex extrasystoles, however no studies involve patients with chronic chagasic cardiopathy.

In the evolution of chronic chagasic cardiopathy the occurrence of frequent and complex ventricular extrasystoles is common, often with greater intensity than in other forms of cardiopathies (33). Although few studies have been done, there are suggestions that the presence of complex arrhythmias holds some relation to greater myocardial aggression (8) and a greater incidence of sudden death (34). There are not, at this time, randomized studies in progress to answer whether some form of antiarrhythmic therapy could benefit these patients.

In order to learn the prognostic value of ventricular tachycardia induced by programmed stimulation, 72 carriers of chronic chagasic cardiopathy and frequent ventricular extrasystoles were submitted to electrophysiologic study. All the patients were oligosymptomatic, with average ejection fraction of VE at $60 \%$ on the echocardiogram. The number of extrasystoles per hour was from 400 to 1200 , and the percentage of non-sustained ventricular tachycardia was $35 \%$. Programmed ventricular stimulation did not induce sustained ventricular tachycardia in any patient and there was only one case of spontaneous sustained ventricular tachycardia in an average follow-up of 36 months. These data suggest that patients with chronic chagasic cardiopathy with normal ventricular function and frequent ventricular arrhythmias, without syncope, show good clinical evolution in the medium term, and thus electrophysiologic study is unnecessary.

With the objective of identifying populations of chagasic patients with greater risk of occurrence of sustained ventricular tachycardia, clinical variables and non-invasive evaluations were compared in two patient populations: the first, symptomatic and with recurrent sustained ventricular tachycardia; the second, oligosymptomatic, formed by patients with frequent ventricular extrasystoles without sustained ventricular tachycardia (9). The variables related to the presence of 
sustained ventricular tachycardia, in multivariate analysis, were: male sex, age ( $>50)$, ejection fraction smaller than $50 \%$ on the echocardiogram and the presence of complex ventricular extrasystoles. In the first group sustained ventricular tachycardia was induced in $90 \%$ of the patients, while in the second none were induced. This data suggests that electrophysiologic study could be useful for this subgroup, patients with a greater risk of sustained ventricular tachycardia; however, this information needs validation through prospective study.

\section{CONCLUSION}

Invasive electrophysiologic study is safe for investigating cardiac arrhythmias, furnishing precise electrophysiologic information. The patients with chronic chagasic cardiopathy can benefit from its clinical application, as can the patients of other cardiopathies. Its indication should be made with a critical mind, through the evaluation of the probable benefit to be obtained within the inherent limitations of the method. In this context, and with the results interpreted in light of the clinical chart, electrophysiologic study becomes an important auxiliary tool in the handling of carriers of chronic chagasic cardiopathy and cardiac arrhythmias.

\section{Resumo}

As arritmias cardíacas sāo comuns na evoluçāo da cardiopatia chagásica crônica. O estudo eletrofisiológico é um método de investigaçāo invasiva que tem a capacidade de avaliar a funçāo do nó sinusal, a condução pelo nó atrioventricular, a condução pelo sistema His-Purkinje e o mecanismo das taquicardias. Ele é útil para esclarecimento diagnóstico, em pacientes com pré-síncopes, síncopes e palpitaçōes taquicárdicas, não esclarecidas pela investigação não invasiva. É um procedimento fundamental no manuseio de pacientes submetidos a terapêutica nāo farmacológica, em particular nos ressuscitados de morte súbita. Pacientes com cardiopatia chagásica crônica podem beneficiar-se do estudo eletrofisiológico quando bem selecionados. 
1. ANGELIM, F.; SCANAVACCA, M.; SOSA, E. et al. Tratamento cirúrgico dirigido da taquicardia ventricular sustentada recorrente na miocardiopatia chagásica crônica. Resultados tardios. Arq Bras Cardiol 55:B-55, 1990.

2. BARBOSA, E.C.; ALBANESI, F.M.; GINEFRA, P. et al. Avaliação da síncope em pacientes com cardiopatia chagásica crônica. Arq Bras Cardiol 57(4):301-305, 1991.

3. BHANDARI, A.K. \& RAHIMTOOLA, S.H. - Indications for intracardiac electrophysiologic testing in survivors of acute myocardial infarction. Discution. Circulation 75-III: 166-167, 1987.

4. BENCHIMOL, C.B. - Distúrbio da condução na Cardiopatia Chagásica Crônica. Estudo eletrofisiológico em 81 casos. ARS Curandi- Cardiologia 2:10-25, 1980.

5. BIGGER, J.T.; FLEISS, J.L.; KLEIGER, R. et al. - The relationships among ventricular arrhythmias, left ventricular dysfunction, and mortality in the 2 years after myocardial infarction. Circulation 69:250-258, 1984.

6. BRUGADA, P.; BRUGADA, J.; MONT, L. et al. - A new approach to the differential diagnosis of a regular tachycardia with a wide QRS complex. Circulation 83:1649-1659, 1991.

7. BUGADA, P.; LEMERY, R.; TALAJIC, M. et al, - Treatment of patients with ventricular tachycardia or ventricular fibrillation: First lessons from the "Parallel Study". Cardiac Arrhythmias: Where to go from here? Pedro Brugada and Heins J J Wellens, New York, Futura Publishing Co, 1987. p. 477-469.

8. CARRASCO, H.A.; GUERRERO, L.; PARADA, H. et al. Ventricular arrhythmias and left ventricular myocardial function in chronic chagasic patients. Int J Cardiol 28:3541, 1990.

9. CURY, H.; SOSA, E.; SCANAVACCA, M. et al. Identificação de fatores de risco para ocorrência de taquicardia ventricular sustentada espontânea na cardiopatia chagásica crônica. Arq Bras Cardiol supl (in press), 1994.

10. DE PAOLA, A.A.V.; MIYAMOTO, M.H.; CIRENZA, C. et al. - Técnicas ablativas para o tratamento de arritmias refratárias em pacientes com cardiopatia chagásica crônica. Arq Bras Cardiol 57:C3, 1991.

11. DHINGRA, R.C.; PALILEO, E.; STRASBERG, B. et al. Significance of HV interval in 517 patients with chronic bifascicular block. Circulation 64:1265-1271, 1981.

12. DIAS, J.C.P. - História natural. In: Cançado, J.R. e Chuster, M. (eds): Cardiopatia Chagásica. Belo Horizonte, Fundação Carlos Chagas, 1985. 99 p.

13. ECHT, D.S.; LIEBSON, P.R.; MITCHELL, L.B. and the CAST Investigators - Mortality and morbidity in patients receiving Encainide, Flecainide, or Placebo. N Engl J Med 324:781-788, 1991.

14. GALVÃO, S.; VASCONCELOS, J.T.; COSTA, E. et al. Ablação por cateter no tratamento de taquicardias ventriculares refratárias. 31 sessões em 05 anos de experiência. Arq Bras Cardiol 61:II-25, 1993.

15. GRABOYS, T.B.; LOWN, B.; OODRID, P.J. \& DE SILVA, R. - Long-Term survival of patients with malignant ventricular arrhythmias treated wit antiarrhythmic drugs. An J Cardiol 50:437-443, 1982.

16. JOSEPHSON, M.E. \& SEIDES, S.F. - Clinical Cardiac Electrophysiology. Techniques and Interpretations. Philadelphia, LEA and FEBIGER, 1979.

17. KAPOOR, W.; HAMMIL, S. \& GERSH, B. - Diagnosis and natural history of syncope and the role of invasive electrophysiologic testing. Am J Cardiol 63:730-734, 1989.

18. LOPES, E.R. - Morte súbita em área endêmica em doença de Chagas. Sua importância médico-legal.Uberaba, 1981 [Tese - Faculdade de Medicina do Triângulo Mineiro].

19. LOPES, E.R.; CUNHA, L.F.L.R.; SANTOS, T.A.M. et al, Variações circadianas diárias e semanais na morte súbita da doença de Chagas. Arq Bras Cardiol 61(6):345-348, 1993.

20. LUU, M.; STEVENSON, W.G.; STEVENSON, L.W. et al. Diverse mechanism of unexpected cardiac arrest in advanced heart failure. Circulation 80:1675-1680, 1989.

21. MAIA, I.G.; SÁ, R.S.; LOYOLA, L.H. et al. - O nódulo sinusal na cardiopatia chagásica crônica. Arq Bras Cardiol 40:91-96, 1983.

22. MANDEL, W.J.; HAYAKAWA, H.; DANZIG, R. \& MARCUS, H.S. - Evaluation of sinoatrial node function in man by overdrive pacing. Circulation 44:59-66, 1971.

23. MANGIARDI, L.M.; BONAMINI, R.; CONTE, M. et al. Bedside evaluation of atrioventricular block with narrow QRS complexes: usefulness of carotid sinus massage and atropine administration. Am J Cardiol 49:1136-1145, 1982.

24. MARTINELLI FILHO, M. - Cardiopatia Chagásica Crônica e Síncope: aspectos clínicos e eletrofisiológicos. São Paulo, 1992 [Tese de Doutorado - Faculdade de Medicina da USP].

25. McANULTY, J.; RAHIMTOOLA, S.H.; MURPHY, E. et al. - Natural history of "high risk" bundle branch block. Final report of a prospective study. N Engl J Med 307:137-149, 1982.

26. MENDOZA, I.; CAMARGO, J.; MOLEIRO, F. et al. Sustained ventricular tachycardia in chronic chagasic myocarditis: electrophysiologic and pharmacologic characteristcs. Am J Cardiol 57:423-427, 1986.

27. MORLEY, M.; ABUD, M.; SOSA, E. \& SCANAVACCA, M. - Avaliaçâo do padrão eletrocardiográfico das taquicardias ventriculares sustentadas na cardiopatia chagásica crônica. Arq Bras Cardiol 61:II-25, 1993.

28. OYARZUN, R.; BRUGADA, P.; SMEETS, J. et al. Electropharmacologic versus empirical approach of sustained ventricular arrhythmias in patients with coronary artery disease. The Heidelberg-Maastricht study. Arq Bras Cardiol LIII:1-52, 1989.

29. PIMENTA, J.; MIRANDA, M. \& PEREIRA, C.B. Electrophysiologic finds in longterm asymptomatic chagasic individuals. Am Heart J 106:374-380, 1983.

30. PIMENTA, J.; MIRANDA, M. \& SILVA, L.A. - Abnormal atrioventricular nodal response patterns in patients with longterm Chagas disease. Chest 78:310-315, 1980. 
31. RAHIMTOOLA, S.H.; ZIPES, D.P.; AKHTAR, M. et al. Consensus statement of the Conference on the State of Art of Electrophysiologic Testing in the Diagnosis and Treatment of Patients with Cardiac Arrhythmias. Circulation 75(III):311, 1987.

32. RASSI, S.; JATENE, J.; FARINA, R. et al. - Avaliação eletrofisiológica do sistema His-Purkinje após sensibilização com procainamida. Arq Bras Cardiol 45:106, 1985.

33. RASSI JR., A.; RASSI, A.G.; RASSI, S. et al. - Arritmia ventricular na insuficiência cardíaca de etiologia chagásica e não chagásica. Arq Bras Cardiol 61:II-29, 1993.

34. SANTANA, O.O. - Arritmia ventricular e evolução clínica de pacientes na fase crônica da doença de Chagas. Salvador, 1987 [Tese - Universidade Federal da Bahia].

35. SCANAVACCA, M.I.; SOSA, E.A.; LEE, J.H. et al. Terapêutica empírica com amiodarona em portadores de miocardiopatia chagásica crônica e taquicardia ventricular sustentada. Arq Bras Cardiol 54 (6):367-371, 1990.

36. SCANAVACCA, M.; SOSA, E.; MARTINELLI, M. et al. Cardioversor/desfibrilador automático implantável. Experiência inicial. Arq Bras Cardiol 57:C-1, 1991.

37. SCANAVACCA, M.; SOSA, E. \& MARTINELLI, M. Manuseio de drogas antiarrítmicas em pacientes portadores de Marcapasso. Arq Bras Cardiol 51/6:471-476, 1988.

38. SCHEINMAN, M.M.; PETERS, R.W.; SAUVE, M.J. et al. - Value of HQ interval in patients with bundle branch block and the role of prophylactic permanent pacing. Am J Cardiol 50:1316-1322, 1982.
39. SCHEINMAN, M.M.; STRAUS, H.C. \& ABOTT, J.A. Electrophysiologic testing for patients with sinus node dysfunction. J Electrocardiol 12:211-216, 1979.

40. SOSA, E.; BARBERO, M.; SCALABRINI, A. et al. Surgical treatment of recurrent ventricular tachycardia in chronic chagasic heart disease. X World Congress of Cardiology. Abstract book. 1986, p 117.

41. SOSA, E.; SCALABRINI, A.; RATI, M. et al. - Successful catheter ablation of the "origem" of recurrent ventricular tachycardia in chronic chagasic heart disease. J Electrophysiol 1:58-61, 1987.

42. SOUZA, I.A. \& DE PAOLA, A.; CIRENZA, C. et al. Efeitos eletrofisiológicos da amiodarona em pacientes portadores de cardiopatia chagásica crônica e taquicardia ventricular. Arq Bras Cardiol 57:C2, 1991.

43. STRAUSS, H.C.; BIGGER, J.T.; SAROFF, A.L. \& GIARDINA, E.G.V. - Electrophysiologic evaluation of sinus node function in patients with sinus node dysfunction. Circulation 53:763-776, 1976.

44. SWERDLOW, C.D.; WINKLE, R.A. \& MASON, J.W. Determinants of survival in patients with ventricular tachyarrhythmias. N Engl J Med 308:1436-1442, 1983.

45. TAKEHARA, K.; SCANAVACCA, M.; SOSA, E. et al. Aspectos anatomopatológicos do foco da taquicardia ventricular sustentada recorrente da cardiopatia chagásica crônica. Arq Bras Cardiol 55: B-68, 1990. 